\title{
Negatives Scoping Over Verbal Clauses in Some Arabic Varieties
}

\author{
Al Zahrani Mohammad, Alzahrani Salih \\ Taif University, Makkah Province, Saudi Arabia
}

\begin{abstract}
Both Classical Arabic (CA) and Modern Standard Arabic (MSA) use the six negative particles: laa, maa, laysa, lam, lamma, and lan. Other Arabic varieties have only two negative particles. For instance, Hijazi Arabic (HA) uses laa and maa. This shows that the three varieties (CA, MSA, and HA) have the same underlying negatives, namely, laa and maa, but CA and MSA have a number of inflected forms of laa that HA does not have. The paper shows how HA uses the two negatives when scoping over verbal clauses while the other two varieties, i.e., CA and MSA, use all the six negatives. It is worthy of note here that HA is descendant from CA which has the six negatives. This suggests that HA must have lost the inflected variants of laa..
\end{abstract}

Keywords: Standard Arabic, Classical Arabic, Arabic Varieties, Negation, Verbal Clauses, Scope

\begin{tabular}{llll}
\hline List of Abbreviations and Symbols & & \\
\hline$\varnothing$ & Absence of marking system & Ind & Indicative mood \\
$*$ & Ungrammatical & Juss & Jussive mood \\
1 & First person & $\mathrm{M}$ & Masculine \\
2 & Second person & MSA & Modern Standard Arabic \\
3 & Third person & Neg & Negative \\
Acc & Accusative case & Nom & Nominative case \\
CA & Classical Arabic & Pf & Perfective form of verb \\
Det & Determinative & pl & Plural \\
dl & Dual & P & Preposition \\
F & Feminine & sg & Singular \\
Gen & Genitive & HA & Hijazi Arabic \\
Impf & Imperfective form & Subjn & Subjunctive mood \\
\hline
\end{tabular}

\section{Introduction}

Al Zahrani (2014a) addressed the classical Arabic (CA), modern standard Arabic (MSA), and Hijazi Arabic (HA) negatives in nominal clauses. This paper shows the negatives in the same verities when dominating verbal clauses. This includes, on the one hand, the CA and MSA negatives laa, maa, laysa, lam, lamma, and lan; and the HA negative maa, on the other hand. It shows how the functions and meanings of all the CA and MSA verbal negatives laysa, lam, lamma, and lan have been transferred to one HA negative,

Al Zahrani Mohammad, Ph.D., associate professor, Foreign languages Department, Faculty of Arts, Taif University, Makkah, Saudi Arabia.

Alzahrani Salih, Ph.D., assistant professor, Foreign languages Department, Faculty of Arts, Taif University, Makkah, Saudi Arabia. 
namely _ maa. It turns out that HA retains the negatives laa and maa, but has lost all the other forms. The paper also shows that HA has lost all the morphological case markers, which is not the case in CA and MSA. In this paper, we start by a CA and MSA negative form to show how negation is coded in these varieties by that negative form. Notice that we will not investigate the minor differences between CA and MSA since the paper assumes that the negatives of these two varieties show the same functions. Then, we show how HA encodes negation by the same negative form or by an alternative form carrying the function of the lost negative particle. The negative laa is the first particle under discussion.

\section{The Negative Particle laa in CA and MSA}

Ul-Haq (1984) proposed that the negative laa is used less frequently before perfective forms and it has two different connotations. The first one, if the sentence is optative, it expresses the meaning of "may never" with no morphological effects on the verbs, and according to Wright (1967), this is used in blessings and curses.
(1) laa
faz-a
Neg
win-Pf
al- $ð^{\varsigma}$ alim-u
Det-oppressor-Nom

"May the oppressor never win!"
(2) laa
raPit-a
Neg
see-2sg-Pf
Sara-n
evil-Acc

"May you never see any harm!"

The second connotation is when the negative laa is used before the perfective where it denotes the negation of the simple past and, in this case, it has to be repeated to express the formal meaning of "neither...nor" in English.
(3) $l a a$
akal-a
$w a$
laa
Sarib-a
Neg
eat-Pf
and
Neg
drink-Pf

"He neither ate nor drank."

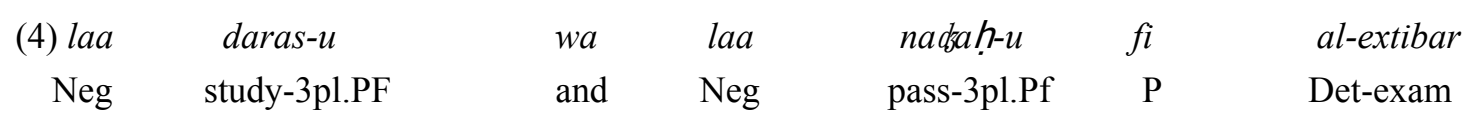

"They neither studied nor passed the exam."

These syntactic structures exhibit the restricted use of the negative laa when occurring with the perfective forms. This is not the case when it occurs with the imperfective forms as it is quite frequent in CA and MSA for the negative particle laa to occur before the different moods of the imperfective. Benmamoun (2000) argued that the imperfective is the default form of the verb (the non-finite form); it is also argued by Benmamoun (1992), Ouhalla (1993), and Shlonsky (1997) that the imperfective in Arabic does not carry tense. The different moods of the imperfective "are distinguished by the vowel of the third radical" (Thatcher, 1922, pp. 76-77). These moods are the indicative, which is indicated by adding the vowel- $u$, the subjunctive, which is indicated by adding the vowel- $a$, and the jussive, that is left without a vowel.

The negative laa denotes negation in the simple future once used with a verb in the indicative mood. However, it has no morphological effects with such a mood.
(5) Pinnahu
laa
yan dah $h-u$
al-kasul-u
Verily
Neg
pass-Ind
Det-lazy-Nom

"Verily, the lazy (student) does not pass." 
With the subjunctive, the particle laa before the imperfective requires a subjunctivizing element. It must be preceded by either ?an, li, li ?an, ћatta, kay, or likay to change the verb mood from indicative to subjunctive (Ryding, 2005) as shown in (6-8) below. Notice that li Pan and likay are created by prefixing the particle $l i$ to the elements Pan and kay respectively. The elements ћatta and kay/likay are glossed according to their meanings, i.e., "in order to" and "so that" respectively.
(6) jajibu
Pan
laa
tal Gab-a
fi
al-Sari $\mathcal{G}-i$
necessary
C Neg
play-Subjn
Det-street-Gen

"You must not play in the street."

Literally: It is necessary that, not to play in the street.
(7) $u d r o s$
ћatta
laa
tafsal-a
$f i$
al-extibar- $i$

Study

in order to

Neg

fail-Subjn

$\mathrm{P}$

Det-exam-Gen

"Study in order not to fail in the exam."
(8) udros
(i)kay
laa
taffal-a
fi
al-extibar-i
Study
so that Neg
fail-Subjn
$\mathrm{P}$
Det-exam-Gen

Lit: "Study! so that (you) will not fail in the exam."

The example in (6) shows that both the subjunctive element Pan and the verb yajibu (it is necessary that) are followed by the negative laa that selects for the subjunctive mood of the verb tal Gab. The examples in (7-8) show the subjunctivizing elements ћatta and (li)kay that have changed the verb mood to subjunctive.

With the jussive, the particle laa is used before the imperfective to indicate prohibition where it is called "the laa of prohibition" (Ibn Aqeel, 1980, p. 349). When using laa to show the prohibitory sense, the verb mood must change into the jussive mood which has no overt marker. Therefore, the sign " $\varnothing$ " is used.

$\begin{array}{ccllll}\text { (9) } \text { jajibu } & \text { Pan } & \text { ta Pti-ya } & \text { wa } & \text { tal } \text { Sab-a } & \text { ma } \text { Sa-na } \\ \text { must } & \mathrm{C} & \text { come-Subjn } & \text { and } & \text { play-Subjn } & \text { with-us }\end{array}$

"You must come and play with us."

\begin{tabular}{|c|c|c|c|c|}
\hline (10) laa & ta $2 t i-\varnothing$ & $w a$ & laa & \\
\hline
\end{tabular}

"Do not come and do not play with us."

In (9), the sentence is in the subjunctive mood as it has the subjunctivizing particle, i.e., the complementizer Pan. Therefore, the verbs have inflected for the subjunctive mood ta?ti-ya and tal $a b-a$ as shown by the subjunctive marker- $a$. In (10), the laa of prohibition causes the verb mood to change into jussive. The next section shows how HA uses the negative laa in very restricted structures.

\section{The Negative Particle laa in HA}

With the perfective, laa is used in optative sentences where the sentence usually starts with the phrase Allah laa meaning "May God not". However, the phrase Allah laa will change the verb aspect from perfective to imperfective with the loss of the perfective marker, $-a$.
(11) Allah laa
ya-d $\xi$ Sal- $\varnothing$
al- $ð^{5}$ alim
$y a-f u z-\varnothing$
God Neg
Impf-make- $\varnothing$
Det-oppressor
Impf-win- $\varnothing$

"May Allah not allow the oppressor to win."
(12) Allah laa
yu-wari-k-Ø
Sara-Ø 
God Neg Impf-see-2sgAcc-Ø harm-Ø

"May Allah never show you any harm."

The examples in (11) and (12) show how good and bad wishes are coded in HA by virtue of the negative laa followed by imperfective forms.

With the imperfective, laa is also used when behaving as a particle of prohibition to convey the meaning of "do not" in English. This laa is followed by the jussive mood that has no overt marker.

$\begin{array}{rll}\text { (13) laa } & \text { taktub-Ø } & \text { haða } \\ \text { Neg } & \text { write- } \varnothing & \text { this }\end{array}$

"Do not write this."

Interestingly, HA uses another morpheme to express the prohibitory sense. It is the cautionary morpheme es $\hbar a$. Like the prohibitive laa, es $\hbar a$ is followed by the jussive that is left with no overt marker. However, it differs from the prohibitive laa as it not only commands the addressee but also warns him/her not to do something.
(14) es $\hbar a$
taktub- $\varnothing$
Һаða
Neg
write- Ø
this

"Do not write this."

Furthermore, laa is used in the construction of laa wa laa (neither...nor) with the perfective (15) and only with the indicative mood of the imperfective (16) which has lost its marker in HA.

$\begin{array}{rlrcc}\text { (15) laa } & \text { akal- } \varnothing & \text { wa } & \text { laa } & \text { Sarib- } \varnothing \\ \text { Neg } & \text { eat.Pf- } \varnothing & \text { and } & \text { Neg } & \text { drink.Pf- } \varnothing\end{array}$

"He neither ate nor drank."

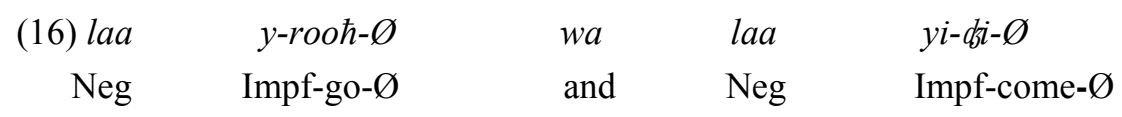

"He neither goes nor comes."

Lit: "He does not go and he does not come."

So far, we have seen that the three varieties use the negative laa to express wishes. However, the varieties differ in that CA and MSA use the negative followed by the perfective forms, whereas HA uses the imperfective form in such a case. We have also seen that CA and MSA use laa to denote negation in the simple future. This function of laa is not found in HA and it has been transferred to the negative maa as shown below.

\section{The Negative Particle maa in CA and MSA}

In both CA and MSA, the negative maa can select for a perfective or an imperfective verb form. It is used before the perfective form (17) and only before the indicative mood of the imperfective form to show definite or absolute negation where it has no morphological effects on verbs it negates (Wright, 1896; 1898).
(17) $m a a$
ta Salam- $u$
al-faranseyat-a
Neg
learn-Pf.3Pl.Ind
Det-French-Acc

"They did not learn the French Language."
(18) $\mathrm{maa}$
ya-takalam-u
al-italiya-ta
Neg Impf-speak-3sg-Ind
Det-Italian-Acc 
"He does not speak Italian."

Both the perfective verb form ta Salam- $u$ and the imperfective verb form ya-takalam- $u$ occur immediately after the negative maa. Notice that in Arabic varieties, including CA, MSA, HA, Faifi Arabic, and Zahrani Arabic, the perfective is associated with the past time interpretation, and the imperfective is associated with the present time interpretation (Al Zahrani, 2013, 2016, 2018; Alzahrani, 2009, 2015, 2016).

Like laa in the correlative structure laa wa laa, the particle maa can be used only before laa to form the correlation, so it is maa wa laa but not *laa wa maa. This has led some linguists to consider wa laa one compound morpheme for the correlative structure. This construction, however, would mean the same as laa wa la like the English "neither ...nor". The difference between them is that laa wa laa would negate the simple past as in (3, 4, and 15) above but maa wa laa indicates the absolute negation as in (19), adopted from Rammuny (1978, p. 253).

\begin{tabular}{|c|c|c|c|c|c|c|}
\hline (19) maa & $d_{\sim}^{\text {rarab-tu }}$ & $w a$ & laa & Satam-tu & ahad-an & $f i$ \\
\hline $\mathrm{Neg}$ & hit-1sg.Pf & and & Neg & abuse-1sg.Pf & one-Acc & $\mathrm{P}$ \\
\hline
\end{tabular}

"I neither hit nor abused anyone in my life."

Interestingly, maa with the perfective, can show negation where the past is connected to the present (Harrama, 1983b). In such a case, we must have ba $d_{d u}$ meaning "yet" where it looks completely like the negative particle lam; but the former does not affect the form of the verb like the latter. Consider the example below.

$\begin{array}{cccc}\text { (20) maa } & \text { afraq-a-t } & \text { al-Sams- } u & b a \varsigma d u \\ \text { Neg } & \text { rise-Pf-F } & \text { Det-sun-Nom } & \text { yet }\end{array}$

"The sun has not risen yet." (Rammuny, 1978, p. 253).

$\begin{array}{rlll}\text { (21) lam } & t \text { - } u \text { friq } & a l-\int a m s-u & b a \varsigma d u \\ \text { Neg } & \text { Impf.3sg.F-rise.Juss } & \text { Det-sun-Nom } & \text { yet }\end{array}$

"The sun has not risen yet."
(22) lam
tufriq
al-Sams- $u$
Neg rise-Juss
Det-sun-Nom

"The sun did not rise."

It is worthy to note that the absence of the adverbial marker $b a \oint d u$ in (20) makes the interpretation in the past "the sun didn't rise", which is similar to (17) with the negative maa, and to (22) with the negative lam. Also, the presence of the adverbial element makes both maa and lam convey the same meaning of "the sun has not risen yet". This shows that the same function of lam can be expressed by the negative maa. This may account for the absence of lam in HA as shown in Section "0". The following section shows how maa behaves in HA.

\section{The Negative Particle maa in HA}

The HA negative maa behaves completely the same as CA and MSA negative maa in that it negates the absolute past when coming before the perfective and/or the imperfective. Also, it is used in the correlative structure maa wa laa. In all three varieties, the negative laa has no morphological effects on the verb forms following it. For the exceptive particle $b a \oint d u$, HA uses the morpheme /baqi/ which conveys the same meaning (see0"). Once again, with the imperfective, HA has lost the marking system of the mood inflections. 

(23) $m a a$
a fraq-a- $t$
al-Sams
Neg
rise-Pf-F
Det-sun

"The sun did not rise."
(24) $m a a$
yi-tkalam- $\varnothing$
al-italiyah
Neg Impf-speak-3sg.M- $\varnothing$
Det-Italy

"He does not speak Italian."
(25) maa
yi-tkalam- $\varnothing$
al-italiyah wa laa
al-faraneyah
Neg
Impf-speak-3sg.M- $\varnothing$
Det-Italy and Neg
Det.French

"He neither speaks Italian nor French."

Examples (23-25) show that the HA negative maa can be followed by the perfective or the imperfective, which are associated with past and present time interpretations respectively. Notice how the complement of the predicate in (25) is followed by the correlative structure wa laa. The next section shows the negative laysa.

\section{The Negative Particle laysa in CA and MSA}

In CA and MSA, this negative element is not frequent with verbal sentences. This, in turn, strengthens the view that considers laysa a verb and not a particle. It is used only before the indicative to negate the simple present and it is mostly used with stative or habitual verbs (Rammuny, 1978; Ul-Haq, 1984). When laysa is inflected for person, number, and gender, there must be a morphophonemic change of the stem. It is important to know that laysa does not need to be adjacent to the verb it negates. The following examples show laysa in different structures with different inflections.
(26) lays-at
Wafa
ta-drus-u
Neg-F Wafa
Impf.F-study-Ind

"Wafa does not study."
(27) laysa
ya-drus-u
Ali
Neg
Impf.M-study-Ind
Ali

"Ali does not study."
(28) las-tumaa
ta-drus-ani
Neg-dl
Impf-study-dl
lil-extibar-i
P-exam-Gen

"You (two) are not studying for the exam."

(29) las-tum

ta-drus-una

lil-extibar-i

Neg-pl.M

Impf.M-study-M.pl

P-exam-Gen

"You (pl.M) are not studying for the exam."
(30) las-tunna
ta-drus-na
lil-extibar-i
Neg-pl.F
Impf.F-study-F.pl
P-exam-Gen

"You (pl.F) are not studying for the exam."

Examples (26-30) posit that the negative particle laysa show full agreement for the Phi features. It inflects for person, gender, and number and that the stem is either/las/ or /lays/ according to the personal pronoun to which it is attached. However, there are cases where laysa shows partial agreement. According to Onaizan (2005, p. 30), the negative laysa is mobile and this mobility, however, may affect somehow the agreement as can be seen in the following two examples.
(31) lays-at
al-banat-u
ya-drus-na 
Neg-F Det-girls-Nom Impf-study-F.pl

"The girls are not studying."
(32) al-banat-u
las-na
ya-drus-na
Det-girls-Nom
Neg-F.pl
Impf-study-F.pl

"The girls are not studying."

In Example (31), the negative laysa precedes the subject, and therefore it does not inflect for number; rather, it appears in the singular form inflecting only for gender. The form of the negative lays-at is similar to Example (26) where the subject is singular. The second example shows a form of the negative laysa, i.e., las-na, inflecting for the grammatical categories of number (plural) and gender (feminine) because it comes after the subject. Investigating the syntactic properties of subject-verb agreement, their placement and how agreement is affected by the subject position will take us far afield; the reader is advised to see the work of other linguists (including Abdelhafiz, 2005; Ahmad-Sokarno, 2005; Aoun \& Benmamoun, 1999; Bahloul \& Harbert, 1992; Carroll, 2000; Harbert \& Bahloul, 2002; Mohammad, 1990, 2000). The next section shows the alternative negative form in HA that negates the structures the CA and MSA negative laysa negates.

\section{Alternative of laysa in HA}

HA has lost the negative particle laysa completely. While this negative morpheme has been lost, the negative maa is used to function in the structures where laysa is used in CA and MSA. The negative maa, needless to say, does not inflect for person, number, or gender in all varieties. Consider the following examples.

$\begin{array}{ccl}\text { (33) } \text { Wafa } & \text { maa } & \text { ta-drus } \\ \text { Wafa } & \text { Neg } & \text { Impf.3sg.F-study } \\ \text { "Wafa does not study." } & \\ \text { (34) } \text { Ali } & \text { maa } & \text { ya-drus } \\ \text { Ali } & \text { Neg } & \text { Impf.3sg.M-study }\end{array}$

"Ali does not study."

Comparing the examples of the negative laysa in (26-32) with the ones in (33-34), one can observe that HA uses the negative maa in the same examples where CA and MSA use laysa. The absence of the negative maa in (33-34) presents the affirmative counterpart of the same examples where the lexical verb ta-drus does not show any morphological changes, i.e., the negative maa does not show any morphological impact on the verb. What one can also observe in (33-34) is that, unlike laysa, the particle maa must be adjacent to the verb it negates, i.e., we cannot separate the negative particle and the verb it negates as we can do with laysa in the varieties of CA and MSA. This accounts for the ungrammaticality of the following example.
(35) * maa
Wafa
ta-drus- $\varnothing$
Neg Wafa
Impf.3sg.F-study- Ø

"Wafa does not study."

\section{The Negative Particle lam in CA and MSA}

This negative is particular to verbal sentences, and more precisely to the imperfective form. It must precede the imperfective form immediately; consequently, it causes the case to change from nominative into jussive. Cantarino (1974, p. 127) proposed that "this construction expresses the negation of the perfective in all its different meanings (except the optative for which laa is the exclusive negation)". Interestingly, the jussive 
verb occurring after lam is imperfective in form and perfective in meaning, and this is exactly the opposite of the negative laysa (not to be) in that laysa is perfective in form and imperfective in meaning (Bedawi, Carter, \& Gully, 2004; Harrama, 1983a).

The negative lam is always followed by the imperfective form in the jussive mood. Compare the following examples.
(36) la Sib-a
al-walad-u
Pf.3sg.Mplay-Ind
Det-boy-Nom

"The boy played."
(37) lam
ya-l Sab- $\varnothing$
al-walad-u
Neg
Impf.3sg.M-play-Juss
Det-boy-Nom

"The boy did not play."

In (36-37), we observe that lam negates the past but the verb form is imperfective, i.e., yal Iab , and it causes the imperfective verb to change its mood into jussive. This change is achieved by deleting the final short vowel, $u$. Once again, the use of lam is used to negate the past and it is, as Aniis (1972) proposed, stronger than negating the past with maa. This in turn suggests that the negative lam inflects for tense. Notice that lam can be used with the time markers baSdu (yet) or Ћatta al Paan (until now) to express negation of the past connected with the present (Rammuny, 1978) as shown in the examples in (38-39).
(38) lam
$a-ð h a b-\varnothing$
ila
al-madrasat $-i$
Neg Pf.1sg-go-Juss
P Det-school-Gen

"I did not go to school."
(39) lam
$a$ ðhab- Ø
ila
al-madrasat-i
$b a \oint d u$
Neg Pf.1sg-go-Juss
P Det-school-Gen
yet

"I have not gone to school yet."

The next section sheds light on the negative lamma, which is very close in functions from lam.

\section{The Negative Particle lamma in CA and MSA}

Like lam, lamma is particular to the perfective form of the verb and it affects the mood of the verb to change it to jussive. It negates the past that extends to the present. Hence, the negative lamma inflects for tense. It is used for the negation of the resultative perfective or of the perfective preceded by qad with the meaning of "had already" (Cantarino 1974, p. 127). The resultative perfective expresses actions started in the past and, as such, completed but understood as still lasting in their results or consequences - thus, equivalent to the imperfective (Ghalayini, 1986, p. 185). Hence, lamma is for negating an action in the past connected with the present.

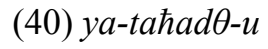
San-ni Impf.3sg.M-speak-Ind
P-1sg.Gen
wa lamma and Neg
ya-ra-Ø-ni Impf.3sg.M-see-Juss-1sg.Gen

"He speaks about me but has not seen me."
(41) ya-taћad $\theta-u$ an-ni wa
lamma
ya-ra-Ø-ni ba $\{d u$ Impf.3sg.M-speak-Ind P-1sg.Gen and Neg Impf.3sg.M-see-Juss-1sg.Gen yet

"He speaks about me but has not seen me, yet."

This function of lamma can be expressed by the negative lam with the morpheme ba Sdu or ћatta al Paan. This shows the very rare use of this negative in CA and MSA (Ayyub, 1957). The fact that its restricted 
structure and meaning has led to its rare use in both verities of CA and MSA can be more plausible reasoning to account for its loss in HA. However, the substitution of lamma for lam does not mean they are entirely the same. There are some similarities as well as some differences between these two negatives.

Traditional Arab grammarians like Ibn Hisham (1985) and Ibn Aqeel (1980) as well as some linguists like Wright (1898), Ul-Haq (1984), and Ghalayini (1986) argued that both negative particles are articular to the imperfective, both affect the mood as they cause it to change to jussive, and both show the negation in the past even followed by the imperfective form of the verb. Therefore, if you say "lam ?aktub" or "lamma Paktub", both structures convey the meaning of "I did not write".

However, the two negatives differ from each other in the following. First, traditional grammarians

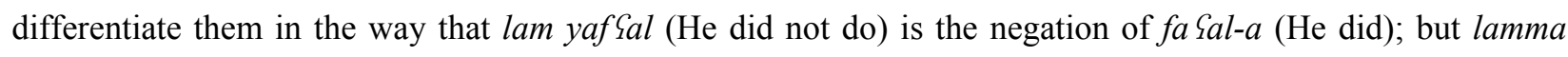

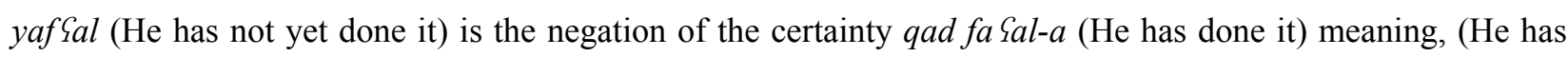
not yet done it, but he will certainly do it afterwards). This concludes that lam is for the negation in the simple past which is equivalent to "did not" while lamma is for the negation of the past that extends to the present "have not yet" (Wright, 1898).

Second, as Ghalayini (1986) proposed, lam is for the absolute negation in the past which may happen afterwards, as in lam af Cal thumma fa Galtu (I did not do, then I did), while lamma is for negating the past connected with the present. Then, you cannot say *lamma af Cal thumma fa Yaltu (*I have not yet done, then I did). Traditional grammarians call it a particle of absorption as it absorbs the whole past time till it connects with the present.

Third, Ibn Aqeel (1980) argued that lam accepts the conditional particle Pin (42a) while lamma does not as shown by the ungrammaticality of (42b).
(42) (a) Pin lam
ta-drus- $\varnothing$
ta-rsub- Ø
If Neg Impf.2sg-study-Juss
Impf.2sg-fail-Juss

"If you do not study, you will fail."
(b) * $\sin$
lamma
ta-drus- $\varnothing$
ta-rsub- Ø
If $\quad \mathrm{Neg}$
Impf.2sg-study-Juss
Impf.2sg-fail-Juss

It is clear that the sentence refers to the future as is expressed by the meaning due to the presence of the conditional particle. The mood of the imperfective verb forms have changed since the particle lam causes the verbs ta-drus and ta-rsub to be in the jussive mood.

Fourth, the use of lamma can suggest a gapping structure. In other words, the verb may be ellipsed after lamma and can be predicted from the context. This is not the case with lam. Consider the following example where the verb adxul (entered) after lamma is ellipsed.

$\begin{array}{cccc}\text { (43) } \text { qaarab-tu } & \text { al-bait-a } & \text { wa } & \text { lamma... } \\ \text { approach-Pf-1sg } & \text { Det-house-Acc } & \text { and } & \text { Neg... }\end{array}$

"I approached the house, but had not yet..."

Intended meaning: "I approached the house, but had not yet entered"

The negative lamma presupposes that the negated action might take place, like saying "lamma usafir" (I have not yet travelled) where it means your travel is soon; but it is not the case with lam. This accounts for the fact that we cannot express impossible negation using lamma, but that is possible with lam as shown in the following example where only lam, but not lamma, is accepted. Note that lamma has the asterisk indicating the ungrammaticality of its use. 


$\begin{array}{lllll}\text { (44) } \operatorname{Lam}\left({ }^{*} \text { lamma }\right) & \text { a-f } \text { - } 9 \text { al- } \varnothing & \text { ma } & \text { laa } & \text { yumkin } \\ \text { Neg } & \text { Impf.1sg-do-Juss } & \text { what } & \text { Neg } & \text { possible }\end{array}$

"I did not do what was impossible."

To conclude, it is clear that lam and lamma are very similar in their functions; and the function of lamma can be conveyed by lam if some adverbial time markers are present.

\section{Alternative of Iam and lamma in HA}

HA does not use the negative particles lam or lamma. Instead, it uses the negative particle maa with adverbial time markers to function like lam and lamma in CA and MSA. This shows that the functional load of the negatives lam and lamma has been transferred to the negative maa. In other words, HA uses the negative particle maa accompanied by the time marker baqi "yet" to show the negation of the past connected to the present. If the time marker baqi is ellipsed, the negation will be like using the particle maa before the perfective in HA compared to its use in MSA (See Sections "The Negative Particle maa in CA and MSA" and "The Negative Particle maa in HA"). Now consider the examples in (45-46).
(45) maa
daras- $\varnothing$
al-walad- $\varnothing$
Neg
Pf.3sg.M.studied- $\varnothing$
Det-boy- $\varnothing$

"The boy did not study."

$\begin{array}{rlcc}\text { (46) maa } & \text { daras- } \varnothing & \text { al-walad- } \varnothing & \text { baqi } \\ \text { Neg } & \text { Pf.3sg.M.studied- } \varnothing & \text { Det-boy- } \varnothing & \text { yet }\end{array}$

"The boy has not studied yet."

These two examples remind the reader of our discussion about maa above where Harrama (1983) claimed that $m a a$ with the perfective is somehow similar to that of lam with the imperfective as they almost convey the same meaning regardless of the claim some grammarians have made that lam negates the remote past while maa negates the near past. It is a matter of stylistic variation only because the meaning is identical. Harrama made this claim because the use of maa + the perfective, or lam + the imperfective, in the above two sentences expresses the negation of "The boy did not study" while the addition of the adverbial time marker baqi conveys the meaning of "The boy has not studied yet". This indicates that the HA maa may behave like lam in MSA; therefore, it functions in HA instead of lam that this variety has lost. The adverbial time word baqi differentiates between the HA maa that is used instead of lam, and the HA maa that is the counterpart of the MSA's negative maa. This supports the argument that the negative maa has the functional load in HA.

Worthy of notice here is the loss of the marking system in HA where all moods markers show no morphological content.

\section{The Negative Particle Ian in CA and MSA}

It is agreed upon by all the grammarians and linguists that lan is always followed by an imperfective verb form in the subjunctive mood denoting negation in the future (Al Zahrani, 2014a, 2014b; Ibn Aqeel, 1980; Ibn Hisham, 1985). This in turn means that the negative lam inflects for tense. Moreover, like lam, this particle compels the verb to change its mood into subjunctive.
(47) $s a$
a-zuur-u
Salih-an
will
Impf.1sg.visit-Ind
Salih-Acc

"I will visit Salih." 

(48) lan
$a-z u u r-a$
Salih-an
Neg
Impf.1sg.visit-Subjn
Salih-Acc

"I will not visit Salih."

Example (47) shows the future morpheme /sa/ that is absent in (48) due to the presence of the future negative particle lan. This function of lan has led some linguists like Cantarino (1974) to propose that lan is the negative counterpart of the imperfective after the future morphemes /sa/ and /sawfa/. This supports Onaizan's (2005) claim that the future negative lan cannot co-occur with the future morphemes /sa/ or /sawfa/; thus, *lan sa aktub, *lan sawfa aktub are ungrammatical.

From this description of lan, it is worth noting that lan behaves in the opposite way of lam in the condition that the latter is not accompanied by any temporal adverbials. This posits that both negatives inflect for tense and are restricted to the imperfective form where lam expresses negation in the past while lan expresses negation in the future.

\section{Alternative of Ian in HA}

As is the case with laysa, lam, and lamma, HA has also lost the negative particle lan. However, it is similar to the other lost particles in that its functions are expressed by virtue of the HA negative particle maa. Nevertheless, the negative maa is not used alone to function on behalf of the lost particle lan. HA uses the future morphemes, namely, $/ b i /$ or $/ \hbar a /$, which are the counterparts of the CA and MSA future morphemes $/ s a /$ and /sawfal, to prefix the verb where all co-operate to function like the negative lan. Hence, the structure of the HA negative maa plus a future morpheme: $[m a a+b i / \hbar a]$ functions like the negative lan in CA and MSA. It is worthy of note here that the two future morphemes can be used interchangeably without any distinctions. It goes without saying that HA has lost the mood marking system, i.e., the particle maa along with the other two morphemes will not affect the form of the verb at all. The following examples show the CA and MSA negative lan and the HA maa with the other morphemes convey the same task of lan.

(49) lan ya-drus- $a$

Ahmad-un

Neg

Impf.3sg.M-study-Subjn

Ahmad-Nom

"Ahmad will not study."
(50) maa
bi-yi-drus- $\varnothing$
Ahmad-Ø
(51) maa
$\hbar a-y i-d r u s-\varnothing$
Ahmad-Ø
Neg
Fut-Impf.3sg.M-study- $\varnothing$
Ahmad-Ø

"Ahmad will not study."

Examples (50-51) show that HA alternatively uses maa, which shows no morphological influence on the lexical verb forms, to scope over the verbal clauses negated by lan in both MSA and CA.

\section{Conclusion}

So far, this paper has addressed negation in verbal sentences in three Arabic varieties: CA, MSA, and HA. Some negatives come with different aspects while others are restricted only to the imperfective. Some of the negative particles can cause the verb form to change as it inflects for different moods.

The CA and MSA laa is used with the perfective in optative sentences or to show the simple past where it must be repeated. This laa has no morphological impact. With the imperfective, it comes with the different moods as it is used with the indicative for regular negation, with the jussive to express prohibitory sense, and 
with the subjunctive, once attached to a subjunctivizing element, to negate the future. The HA laa, on the one hand, looks like the MSA laa where it is used in optative sentences or to show the simple past where it must be repeated. On the other hand, its uses with the imperfective form have transferred to the HA maa.

The CA and MSA maa is used for absolute negation with no inflectional impacts on the perfective and the imperfective forms. Laysa, in CA and MSA, is very infrequent with verbal sentences and this infrequency supports the view of laysa being a verb. However, once laysa occurs with the imperfective, it is used only with the indicative where it does not morphologically affect the verb forms.

The other three negatives lam, lamma, and lan are very restricted to the imperfective form of verbs. Lam and lamma have almost the same function though there are some differences between them. Lam with the jussive has maintained its function primarily to convey regular negation of the past. Like lamma, lam expresses the past connected with the present and this is indicated by certain time markers occurring after the jussive mood of the imperfective form.

On a par with Benmamoun's (2000) findings that in CA and MSA there are only two negatives laa and maa where the others are inflected variants of laa, this paper concludes that CA, MSA, and HA have the same underlying negatives, laa and maa. However, CA and MSA have five inflected variants of laa carrying the functional load; whereas HA has the negative maa carrying the functional load. That is, the HA maa functions instead of the following CA/MSA negatives: (a) laa with the imperfective; (b) maa with the perfective/imperfective; (c) laysa with the indicative imperfective; (d) lam with the jussive; (e) lamma with the jussive, and (f) lan with the subjunctive. The HA maa in verbal clauses does what the six CA/MSA negatives do. We have seen how HA maa has the functional loads of the CA and MSA negatives. When functioning like the negative lam, it is used with the morpheme baq "yet". For lamma, HA uses the combination of lam...baqi instead of the MSA lamma. Finally, HA uses the morphemes $/ \mathrm{bi} /$ or $/ \underline{h} a /$ with the negative maa to function like the MSA lan. It is apparent that HA has lost the different mood endings. The fact that the jussive in CA and MSA is left without a vowel proves why all verb forms in HA look like the CA and MSA jussive mood that has no overt ending markers.

\section{References}

Abdelhafiz, A. S. (2005). Verb agreement in standard Arabic: An analysis in the minimality program. Language and Linguistics, 4(1), 100-120.

Ahmad-Sokarno, A. H. (2005). Verb agreement in standard Arabic: An analysis in the minimality program. Journal of Language and Linguistics, 4(1), 100-120.

Al Zahrani, M. (2013). Morphosyntactic and semantic properties of Hijazi Arabic Modals (Ph.D. thesis, University of Queensland, Brisbane, Queensland).

Al Zahrani, M. (2014a). Negation in non-verbal clauses-modern standard Arabic (MSA) and spoken Hijazi Arabic (SHA). Pakistan Journal of Languages and Translation Studies, 2, 31-49.

Al Zahrani, M. (2014b). The syntactic properties of negatives. US-China Foreign Language, (1), 1-17.

Al Zahrani, M. (2016). Aktionsarten projection and subcategorization. The Internaional Journal of Arabic Linguistics (IJAL), 2(1), 46-69.

Al Zahrani, M. (2018). Morphosyntactic and semantic properties of epistemic modals modifying verbal clauses. In P. G. Medina, R. T. Alonso, and R. V. Escarza (Eds.), Verbs, clauses and constructions: Functional and typological approaches (pp. 149-166). Newcastle: United Kingdom: Cambridge Scholars Publishing.

Alzahrani, S. (2009). Faify Arabic: Clause structure and negation (Unpublished Master's Thesis, University of Queensland, Brisbane, Australia). 
Alzahrani, S. (2015). Topics in the grammar of Zahrani spoken dialect (Unpublished doctotal thesis, University of Newcastle, Australia).

Alzahrani, S. (2016). Ma: and la: take over all the negative particles in Zahrani spoken Arabic. Faculty of Arts Journal, (80), $81-97$.

Aniis, I. (1972). Min Asrari Allughati (4th ed.). Cairo: Maktabatu Al-Anglu Al-Masriyaah.

Aoun, J., \& Benmamoun, E. (1999). Gapping, PF merger, and patterns of partial agreement. In S. Lappin and E. Benmamoun (Eds.), Fragments: Studies in ellipsis and gapping (pp. 175-192). New York; London: Oxford University Press.

Ayyub, A. (1957). Dirasat Naqdeeyah fi Al-Nahw Al-Arabi (Vol. 1). Cairo: Matb'at Mukhaymar.

Bahloul, M., \& Harbert, W. (1992). Agreement asymmetries in Arabic. In Proceedings of the Eleventh West Coast Conference on Formal Linguistics.

Bedawi, E. S. M., Carter, M. G., \& Gully, A. (2004). Modern written Arabic: A comprehensive grammar. London: Routledge.

Benmamoun, E. (1992). Functional and inflectional morphology: Problems of projection, representation and derivation (Ph.D., USC, Los Angeles).

Benmamoun, E. (2000). The feature structure of functional categories: A comparative study of Arabic dialects. New York: Oxford University Press.

Cantarino, V. (1974). Syntax of modern Arabic prose (Vol. 1 \& 2). Bloomington: Indiana University Press.

Carroll, R. (2000). Word order, agreement, and sentential structure in standard Arabic (MA dissertation, California State University Dominguez Hills, California).

Ghalayini, M. (1986). Jami'e Al-Duroos Al-Arabiyah (All the Arabic Lessons) (Vol. 2). Beirut: Al Maktabah Al Asriyah.

Harbert, W., \& Bahloul, M. (2002). Postverbal subjects in Arabic and the theory of agreement. In J. Ouhalla and U. Shlonsky (Eds.), Themes in Arabic and Hebrew syntax (pp. 45-70). Dordrecht: Kluwer.

Harrama, A. M. (1983a). Some aspects of negation in standard Arabic (MA thesis, University of Arizona).

Harrama, A. M. (1983b). Some aspects of negation in modern standard Arabic (MA thesis, University of Arizona).

Ibn Aqeel, A. (1980). Sharh Ibn Aqeel (Ibn Aqeel's Explanations of Arabic) (Vol. 1 \& 2). Beirut: Daru Al-Uloom

Ibn Hisham, A. (1985). Mughni Al-labeeb 'an Lughati Al-I'rab. Damascus: Dar Al-Fikr.

Mohammad, A. (2000). Word order, agreement, and pronominalisation in Standard and Palestinian Arabic (Vol. 181). Amesterdam/Philadelphia: John Benjamins.

Mohammad, M. A. (1990). The problem of subject-verb agreement in Arabic: Towards a solution. In M. Eid (Ed.), Perspectives in Arabic linguistics I (pp. 95-125). Amsterdam: John Benjamins, .

Onaizan, N. (2005). Functions of negation in Arabic literary discourse (Ph.D. thesis, University of Kansas).

Ouhalla, J. (1993). Negation, focus and tense: The arabic laa and maa. Rivisita di Linguistica, 5, 275-300.

Rammuny, R. M. (1978). Functional and semantic developments in negation as used in modern literary Arabic prose after World War I. Journal of Near Eastern Studies, 37, 245-264.

Ryding, K. C. (2005). A reference grammar of modern standard Arabic. Cambridge Cambridge University Press.

Shlonsky, U. (1997). Clause structure and word order in Hebrew and Arabic: An essay in comparative Semitic syntax. New York: Oxford University Press.

Thatcher, G. (1922). Arabic grammar of the written language (2nd ed.). London: Kessinger Publishing

Ul-Haq, Z. (1984). Negation in Arabic: A morphosyntactic and semantic description. (Ph.D. thesis, Indiana University, Indiana).

Wright, W. (1896). A grammar of the Arabic language (3rd ed., Vol. 1). Cambridge: Cambridge University Press.

Wright, W. (1898). A grammar of the Arabic language (3rd ed., Vol. 2). Cambridge: Cambridge University Press.

Wright, W. (1967). A grammar of the Arabic language (3rd ed., Vol. 2). Cambridge: Cambridge University Press. 